\title{
Wechsel im Herausgeberkreis
}

Als Präsident der Schweizer Gesellschaft für Betriebswirtschaft möchte ich Sie auf einen Wechsel im Herausgeberkreis hinweisen. Kollege Wolfgang Stölzle von der Universität St. Gallen ist auf Ende 2015 aus eigenem Wunsch aus dem Herausgeberkreis ausgetreten; für die geleistete Arbeit als geschäftsführender Herausgeber in den letzten beiden Jahren danke ich ihm sehr herzlich. Verschiedene Indikatoren wie die stetig angestiegene Anzahl Downloads von Beiträgen der Zeitschrift zeigen den Erfolg seiner Arbeit. Als neuer geschäftsführender Herausgeber konnte Kollege Pascal Gantenbein von der Universität Basel gewonnen werden. Ich wünsche Pascal Gantenbein viel Erfolg in seinem Amt und den Leserinnen und Leser weiterhin interessante Einsichten bei der Lektüre der Beiträge.

Zürich, im März 2016

Dieter Pfaff

Präsident der Schweizer Gesellschaft für Betriebswirtschaft 